\title{
An Investigation of the Effect of Chitosan on Isothermal Crystallization, Thermal Decomposition, and Melt Index of Biodegradable Poly(L-lactic acid)
}

\author{
Yan-Hua Cai and Li-Sha Zhao \\ Chongqing Key Laboratory of Environmental Materials \& Remediation Technologies, \\ Chongqing University of Arts and Sciences, Yongchuan, Chongqing 402160, China
}

Correspondence should be addressed to Yan-Hua Cai; caiyh651@aliyun.com

Received 30 July 2015; Accepted 15 October 2015

Academic Editor: Heitor L. Ornaghi

Copyright (C) 2015 Y.-H. Cai and L.-S. Zhao. This is an open access article distributed under the Creative Commons Attribution License, which permits unrestricted use, distribution, and reproduction in any medium, provided the original work is properly cited.

Biodegradable chitosan (CS) was introduced into another biodegradable poly(L-lactic acid) (PLLA) to prepare the PLLA/CS composites, and the effect of CS on thermal behavior and melt index of PLLA was investigated using modern testing technologies including optical depolarizer, thermogravimetric analysis instrument, and melt index instrument. The relevant testing results showed that both crystallization temperature and CS concentration affected the isothermal crystallization behavior of PLLA. Compared to neat PLLA, the $t_{1 / 2}$ of PLLA $/ 5 \%$ CS decreased from $2991.54 \mathrm{~s}$ to the minimum value $208.76 \mathrm{~s}$ at $105^{\circ} \mathrm{C}$. However, the $t_{1 / 2}$ of PLLA/CS composites in high crystallization temperature zone was different from that in low crystallization temperature zone. The increase of CS concentration and heating rate made the thermal decomposition temperature of PLLA/CS composites shift to higher temperature. The melt index results indicated that 3\% CS made the fluidity of PLLA become better.

\section{Introduction}

Chitosan (CS) with the advantage of being nontoxic, as a very valuable biodegradable and biocompatible material, has numerous applications in biomedical science [1,2], materials science [3], waste water treatment [4], inhibitors [5], and so forth. The work about in vitro antioxidant activity of CS scaffold materials indicated that the concentration and molecular weight of CS significantly affected the free radical scavenging ability, and the optimal concentration was $0.2 \mathrm{mg} / \mathrm{mL}$ and the carboxymethyl chitosan possessed higher scavenging ability [6]. Pandele and his colleagues prepared the CS/graphene oxide films using solution blending technology. And the addition of $6 \%$ graphene oxide made Young's modulus and tensile strength values exceed those of nacre by about 60 and $20 \%$, and a high cell proliferation rate for the composite films with high graphene oxide content was confirmed by biocompatibility assays [7]. In the aspect of adsorbent, 8hydroxyquinoline-2-carboxaldehydechitosan (CSHQ) Schiff base derived from CS and 8-hydroxyquinoline carboxaldehyde were synthesized to remove copper from aqueous media. The experimental results suggested that CSHQ would be a promising adsorbent for water treatment, and the adsorption of $\mathrm{Cu}$ (II) onto CSHQ Schiff base depended on the $\mathrm{PH}$ value. Meantime, those results also showed that the $\mathrm{Cu}(\mathrm{II})$ adsorption process onto CSHQ obeyed the Langmuir isotherm model well [8]. To improve interfacial adhesion, the CS was used to be as a coupling agent, and the effects of CS with different addition amounts and particle sizes on the thermal properties of polyvinyl chloride/wood flour composites were investigated. The addition of $30 \mathrm{phr}$ CS with the particle size of 180-220 mesh could elevate thermal properties of polyvinyl chloride/wood flour composites [9]. In addition, Wei and his colleagues constructed poly(ethylene oxide)/CS environmentally friendly composites, and these composites processed excellent mechanical properties, thermal stabilities, and shape-memory behavior, with the increase of poly(ethylene oxide) content; Young's modulus and maximum tensile strength exhibited a decrease, but the elongation at break presented an increase [10].

Poly(L-lactic acid) (PLLA) is also typical biodegradable thermoplastic polymer materials as CS. Furthermore, with 
the development of science technology, PLLA has been applied in many fields such as food packaging, automobile, and electronic industry [11-13]. However, there exist some disadvantages including low crystallization degree and slow crystallization rate to restrict the application in more fields. Thus, many related literatures were reported to improve these drawbacks. To improve the crystallization ability of PLLA, Yang et al. [14] investigated the synergistic effect of poly(ethylene glycol) and graphene oxides on the crystallization behavior of PLLA. The results illustrated that poly(ethylene glycol) could improve the chain mobility of PLLA, and graphene oxides acted as the effective nucleation agent to accelerate the crystallization rate of PLLA, respectively. Furthermore, simultaneous addition of both poly(ethylene glycol) and graphene oxides could cause a synergistic effect to improve the crystallization ability of PLLA. Similarly, Chen et al. [15] also confirmed that graphene oxides exhibited nucleation effect for PLLA crystallization. However, the report showed that the presence of the graphene oxides accelerated the thermal degradation of PLLA and resulted in the decrease of PLLA molecular weight.

In this paper, biodegradable CS was introduced into another biodegradable PLLA to prepare the PLLA/CS composites, and the effect of CS on thermal decomposition, isothermal crystallization, and the fluidity of PLLA was investigated. The relevant results may make PLLA/CS exhibit a promising application in biodegradable materials.

\section{Experiment}

2.1. Materials. Poly(L-lactic acid) (2002D) was purchased from Nature Works LLC (USA). Chitosan was obtained from Mianyang Rongsheng Chemical Reagents Company in Sichuan province in China.

2.2. Preparation of PLLA/CS Composites. PLLA and CS were dried for $24 \mathrm{~h}$ before blending, and the blending process of PLLA and CS was similar to that of our previous paper [16].

\subsection{Test}

2.3.1. Isothermal Crystallization Measurement. Isothermal crystallization of PLLA/CS composites was carried out by GJY-III optical depolarizer (Donghua University, China) in the region from $100^{\circ} \mathrm{C}$ to $120^{\circ} \mathrm{C}$.

2.3.2. Thermal Decomposition. The Q500 thermogravimetric analysis (TGA) (TA Instruments-Waters LLC, USA) was used to investigate the thermal decomposition behavior with different heating rate under air flow $(50 \mathrm{~mL} / \mathrm{min})$.

2.3.3. Melt Index. The fluidity of PLLA and PLLA/CS composites was measured by melt index instrument (Beijing Guance Testing Instrument Co., Ltd., China), the measurement temperature was $180^{\circ} \mathrm{C}$, and load is $10 \mathrm{Kg}$.

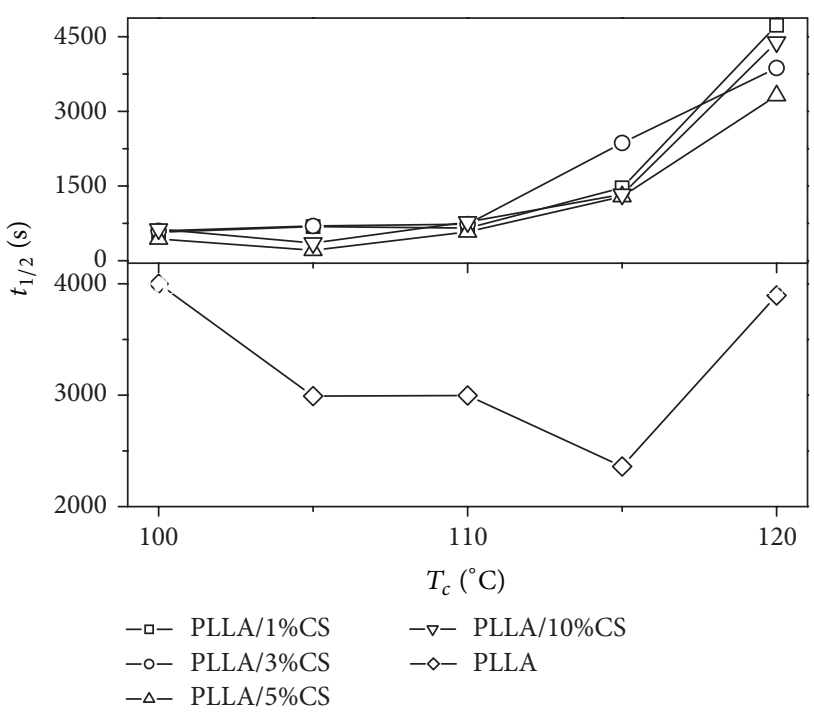

FIGURE 1: The $t_{1 / 2}$ of PLLA and PLLA/CS at different crystallization temperature.

\section{Results and Discussion}

3.1. Thermal Behavior of PLLA/CS Composites. Isothermal crystallization behavior of PLLA/CS composites was investigated. It is observed from Figure 1 that the addition of CS makes the half time of overall crystallization $t_{1 / 2}$ of PLLA significantly decrease, which indicates that $\mathrm{CS}$ can serve as the nucleating agent for PLLA. What is more, it is also clear that both crystallization temperature and CS concentration affect the isothermal crystallization behavior of PLLA. Particularly, the $t_{1 / 2}$ of PLLA is significantly affected by CS concentration in low-temperature section. Upon the addition of 5\% CS, compared to the neat PLLA, the $t_{1 / 2}$ of PLLA decreases from $2991.54 \mathrm{~s}$ to the minimum value $208.76 \mathrm{~s}$ at $105^{\circ} \mathrm{C}$. In contrast, this phenomenon is different in high-temperature section (above $115^{\circ} \mathrm{C}$ ); what is worse, the addition of CS makes the $t_{1 / 2}$ of PLLA increase, and the $t_{1 / 2}$ of the most PLLA with CS is longer than that of the neat PLLA; the reason is that the increasing of movement ability of PLLA molecular chain in high-temperature section makes PLLA not obtain regular structure. At the same time, this phenomenon also indicates that the crystallization temperature is one of the most crucial factors for crystallization process of PLLA.

In addition, Figure 1 also indicates that different CS concentration can exhibit different crystallization behavior; the trend of influence of CS concentration on the crystallization behavior of PLLA is the addition of CS can make the $t_{1 / 2}$ of PLLA decrease, and upon the addition of $5 \%$ CS, the $t_{1 / 2}$ appears as the minimum value.

The isothermal crystallization kinetics of PLLA/CS composites were described using Avrami equation. It is very clear that the relationship of $\log \left[-\ln \left(I_{\infty}-I_{t}\right) /\left(I_{\infty}-I_{0}\right)\right]$ versus logt is linear (see Figure 2), which indicated that Avrami equation is viable for describing the crystallization process of PLLA and PLLA/CS composites. 

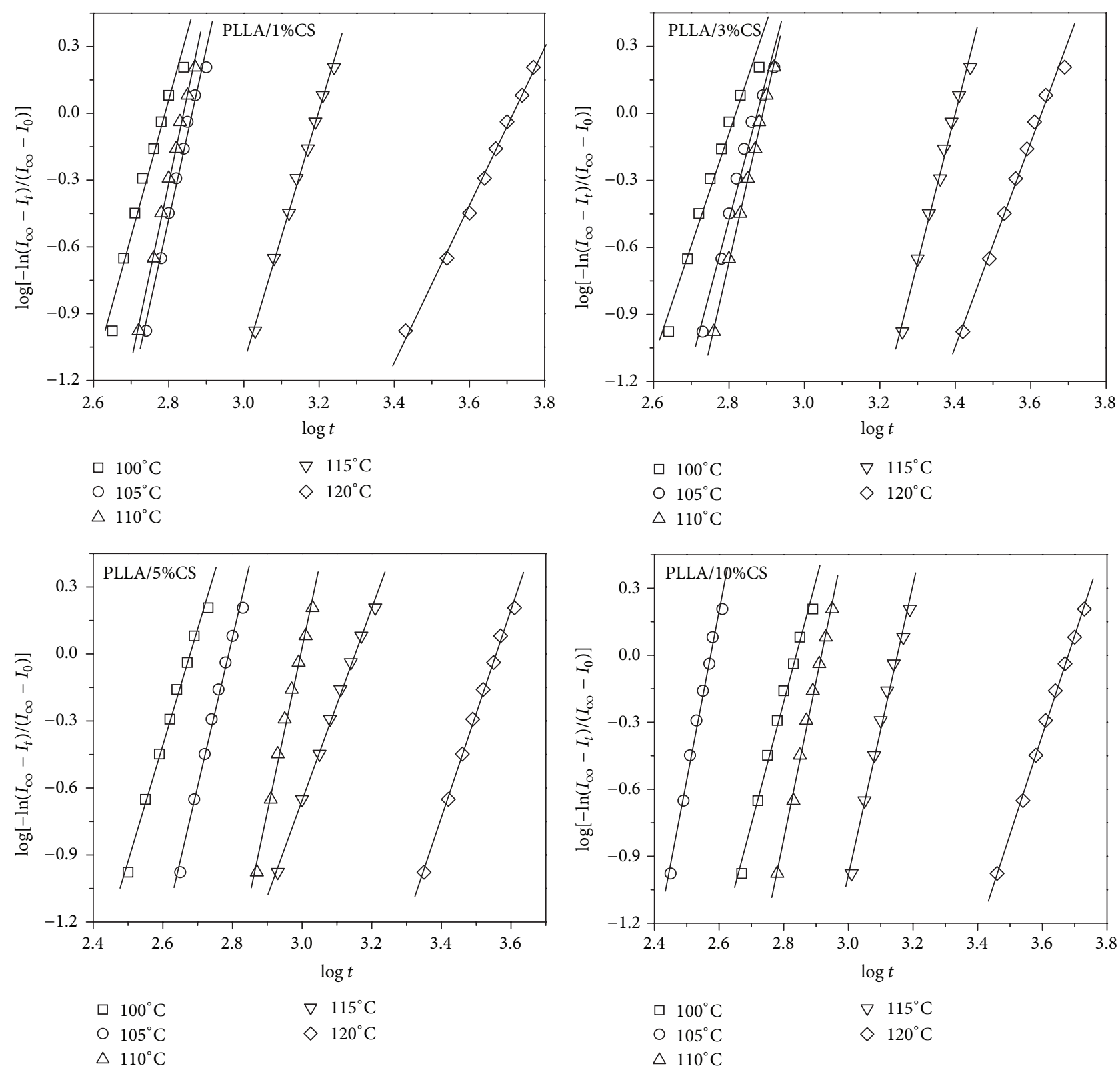

FIgURe 2: The Avrami plots for PLLA/CS composites at different temperature.

The thermal decomposition of PLLA with different CS concentration was shown in Figure 3. As shown in Figure 3, the onset thermal decomposition temperature $\left(T_{o}\right)$ of PLLA/CS composites increases from $345.2^{\circ} \mathrm{C}$ to $347^{\circ} \mathrm{C}$ with increasing of CS content from $1 \%$ to $5 \%$, and the thermal decomposition temperature is also affected by heating rate at the same CS content. Figure 4 shows the effect of the heating rate on the thermal decomposition temperature of PLLA/10\% CS composites. The thermal decomposition trend of PLLA $/ 10 \%$ CS composites at different heating rate is similar, and the $T_{o}$ of PLLA/10\% CS composites increases with an increase of heating rate, resulting from the thermal inertia, and the $T_{o}$ at heating rate of $3,5,10,15$, and $20^{\circ} \mathrm{C} / \mathrm{min}$ are $326.9^{\circ} \mathrm{C}, 335^{\circ} \mathrm{C}, 350.7^{\circ} \mathrm{C}, 354^{\circ} \mathrm{C}$, and $355.8^{\circ} \mathrm{C}$, respectively.

3.2. Melt Index of PLLA/CS Composites. It is well-known that the addition of additive can affect the fluidity of polymer. Here, the melt index of PLLA/CS composites was investigated to reveal the influence of CS on the fluidity of PLLA. The dates from Figure 5 show that the melt mass flow rate (MFR) increases with increasing of CS content, and MFR appears as the maximum value upon the addition of $3 \% \mathrm{CS}$, which indicates that $3 \%$ CS can make the fluidity of PLLA become better. However, the change trend of MFR of PLLA/CS 


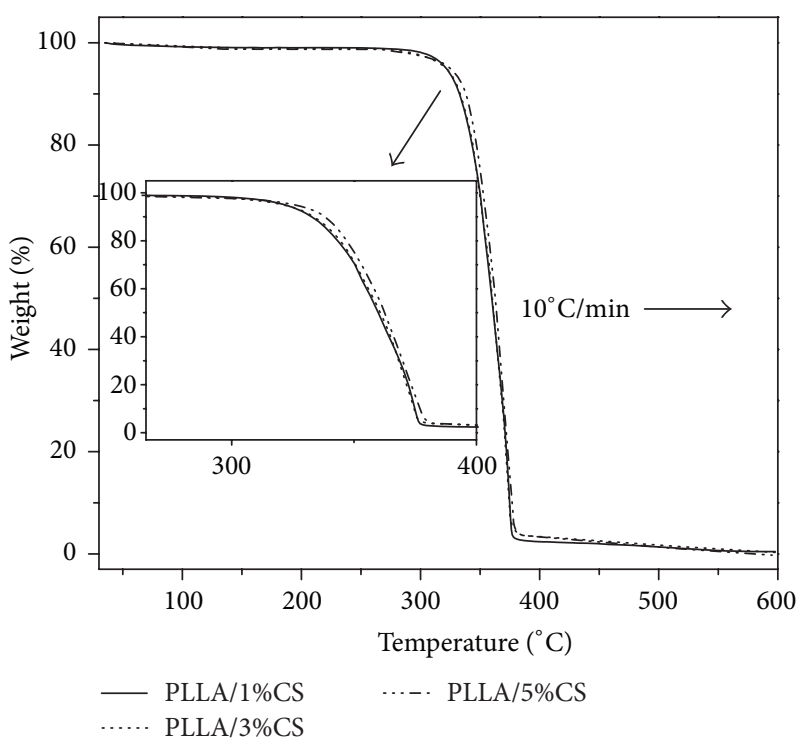

FIGURE 3: The thermal decomposition of PLLA with different CS at a heating rate of $10^{\circ} \mathrm{C} / \mathrm{min}$.

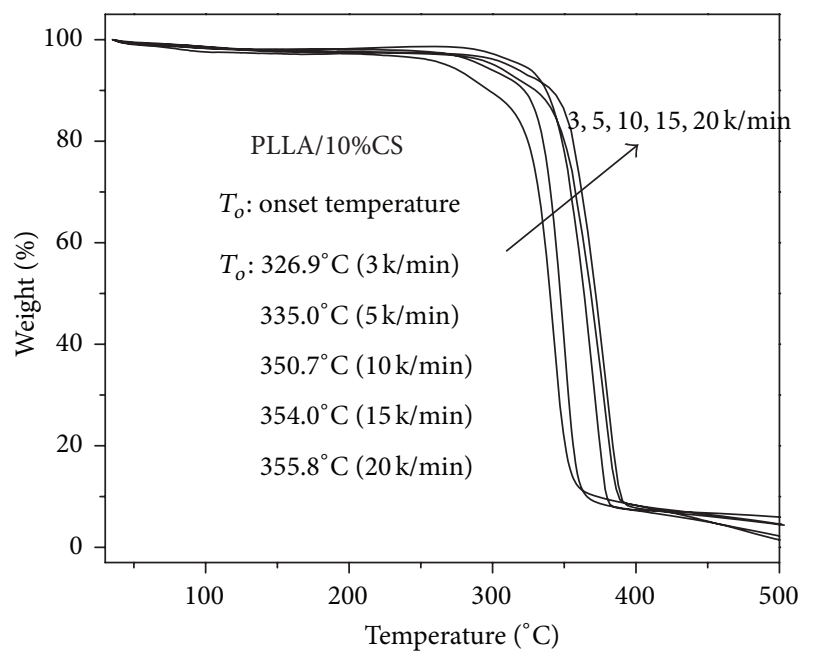

FIgURE 4: The thermal decomposition of PLLA/10\% CS at different heating rate.

composites is irregular; this phenomenon suggested that influence of CS on the fluidity of PLLA is very complicated; on the other hand, this phenomenon may result from the accuracy of measure instrument.

\section{Conclusion}

The isothermal crystallization behavior, thermal decomposition, and the fluidity of PLLA with different CS content were investigated, and isothermal crystallization behavior showed that CS could serve as the nucleating agent for PLLA, and $5 \%$ CS made the $t_{1 / 2}$ of PLLA exhibit the minimum value at $105^{\circ} \mathrm{C}$. The dates from thermal decomposition experiment suggested that the onset thermal decomposition temperature $T_{o}$ of PLLA/CS composites increased with increasing of CS

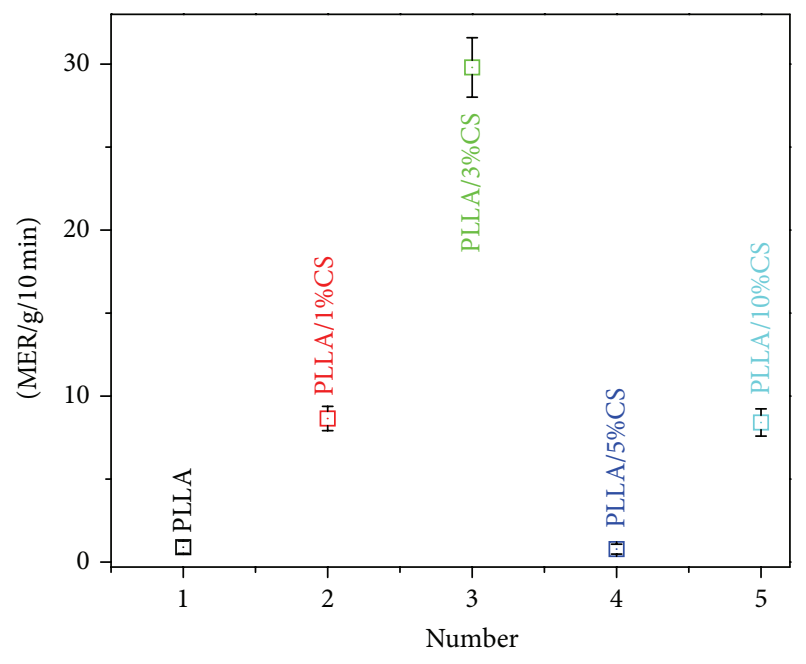

FIGURE 5: The effect of CS content on MFR of PLLA.

content. In addition, the heating rate also affected the $T_{0}$. The melt index of PLLA/CS composites indicated that 3\% CS made the fluidity of PLLA become better, but the influence trend of CS on the fluidity of PLLA was very complicated.

\section{Conflict of Interests}

The authors declare that there is no conflict of interests regarding the publication of this paper.

\section{Acknowledgments}

This work was supported by National Natural Science Foundation of China (Project no. 51403027), Natural Science Foundation Project of CQ CSTC (Project no. cstc2012jjA50001), Foundation of Chongqing Municipal Education Commission (Project no. KJ131202), and Chongqing University of Arts and Sciences (Project no. R2013CH11).

\section{References}

[1] S. Vimal, S. Abdul Majeed, G. Taju et al., "Chitosan tripolyphosphate (CS/TPP) nanoparticles: preparation, characterization and application for gene delivery in shrimp," Acta Tropica, vol. 128, no. 3, pp. 486-493, 2013.

[2] A. Islam, T. Yasin, and I. U. Rehman, "Synthesis of hybrid polymer networks of irradiated chitosan/poly(vinyl alcohol) for biomedical applications," Radiation Physics and Chemistry, vol. 96, pp. 115-119, 2014.

[3] X. Xia, Z. Zheng, Y. Zhang, X. Zhao, and C. Wang, "Synthesis of $\mathrm{Ag}-\mathrm{MoS}_{2} /$ chitosan nanocomposite and its application for catalytic oxidation of tryptophan," Sensors and Actuators B: Chemical, vol. 192, pp. 42-50, 2014.

[4] G. Crini and P.-M. Badot, "Application of chitosan, a natural aminopolysaccharide, for dye removal from aqueous solutions by adsorption processes using batch studies: a review of recent literature," Progress in Polymer Science, vol. 33, no. 4, pp. 399447, 2008. 
[5] M. Li, J. Xu, R. Li et al., "Simple preparation of aminothioureamodified chitosan as corrosion inhibitor and heavy metal ion adsorbent," Journal of Colloid and Interface Science, vol. 417, pp. 131-136, 2014.

[6] H. Li, Q. Xu, Y. Chen, and A. Wan, "Effect of concentration and molecular weight of chitosan and its derivative on the free radical scavenging ability," Journal of Biomedical Materials Research Part A, vol. 102, no. 3, pp. 911-916, 2014.

[7] A. M. Pandele, S. Dinescu, M. Costache et al., "Preparation and in vitro, bulk, and surface investigation of chitosan/graphene oxide composite films," Polymer Composites, vol. 34, no. 12, pp. 2116-2124, 2013.

[8] D. H. K. Reddy and S.-M. Lee, "Synthesis and characterization of a chitosan ligand for the removal of copper from aqueous media," Journal of Applied Polymer Science, vol. 130, no. 6, pp. 4542-4550, 2013.

[9] K. Xu, K. Li, T. Zhong, L. Guan, C. Xie, and S. Li, "Effects of chitosan as biopolymer coupling agent on the thermal and rheological properties of polyvinyl chloride/wood flour composites," Composites Part B: Engineering, vol. 58, pp. 392399, 2014.

[10] H. Wei, F. Zhang, D. Zhang, Y. Liu, and J. Leng, "Shape-memory behaviors of electrospun chitosan/poly(ethylene oxide) composite nanofibrous membranes," Journal of Applied Polymer Science, vol. 132, no. 37, pp. 42532.1-42532.9, 2015.

[11] D. Longano, N. Ditaranto, N. Cioffi et al., "Analytical characterization of laser-generated copper nanoparticles for antibacterial composite food packaging," Analytical and Bioanalytical Chemistry, vol. 403, no. 4, pp. 1179-1186, 2012.

[12] M. Y. Jo, Y. J. Ryu, J. H. Ko, and J.-S. Yoon, "Effects of compatibilizers on the mechanical properties of ABS/PLA composites," Journal of Applied Polymer Science, vol. 125, no. 2, pp. E231-E238, 2012.

[13] V. Kumar, A. Dev, and A. P. Gupta, "Studies of poly(lactic acid) based calcium carbonate nanocomposites," Composites Part B: Engineering, vol. 56, pp. 184-188, 2014.

[14] J.-H. Yang, Y. Shen, W.-D. He et al., "Synergistic effect of poly(ethylene glycol) and graphene oxides on the crystallization behavior of poly(L-lactide)," Journal of Applied Polymer Science, vol. 130, no. 5, pp. 3498-3508, 2013.

[15] H.-M. Chen, X.-C. Du, A.-S. Yang et al., "Effect of graphene oxides on thermal degradation and crystallization behavior of poly(l-lactide)," RSC Advances, vol. 4, no. 7, pp. 3443-3456, 2014.

[16] Y.-H. Cai, "Effects of barium sulfate on thermal behavior of poly(L-lactic acid)," Asian Journal of Chemistry, vol. 25, no. 4, pp. 2170-2172, 2013. 

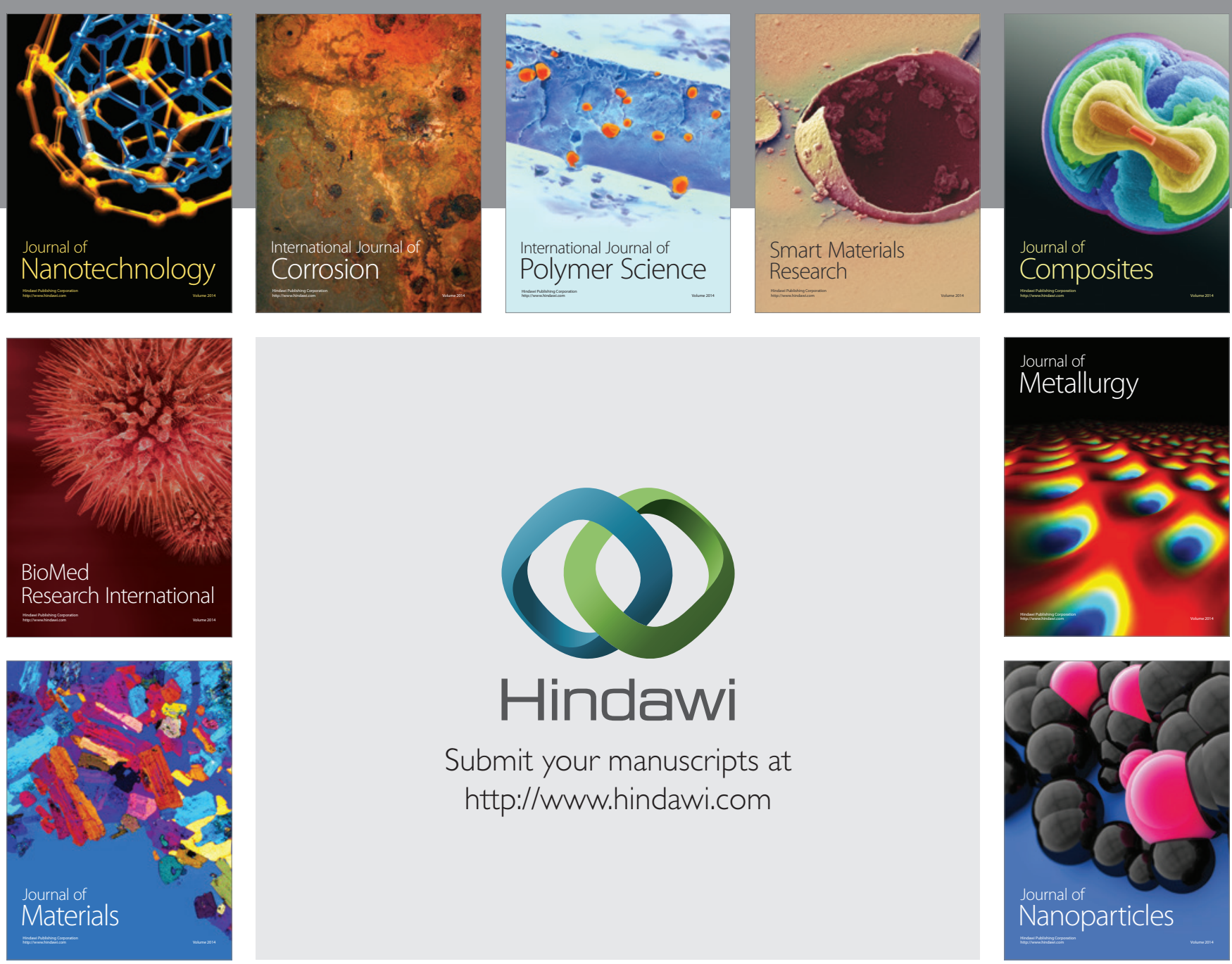

Submit your manuscripts at http://www.hindawi.com
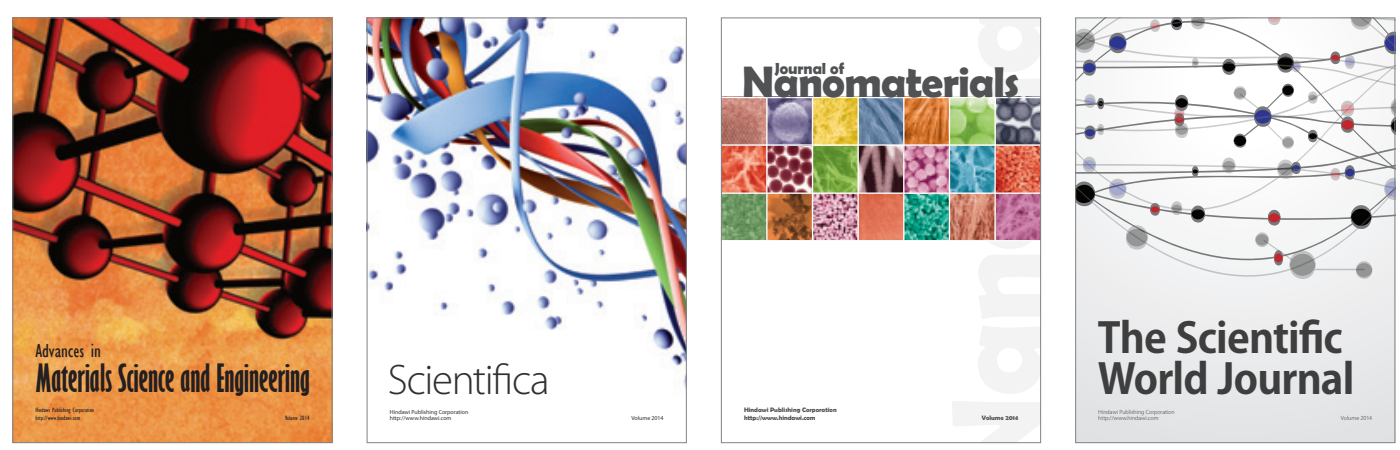

\section{The Scientific World Journal}
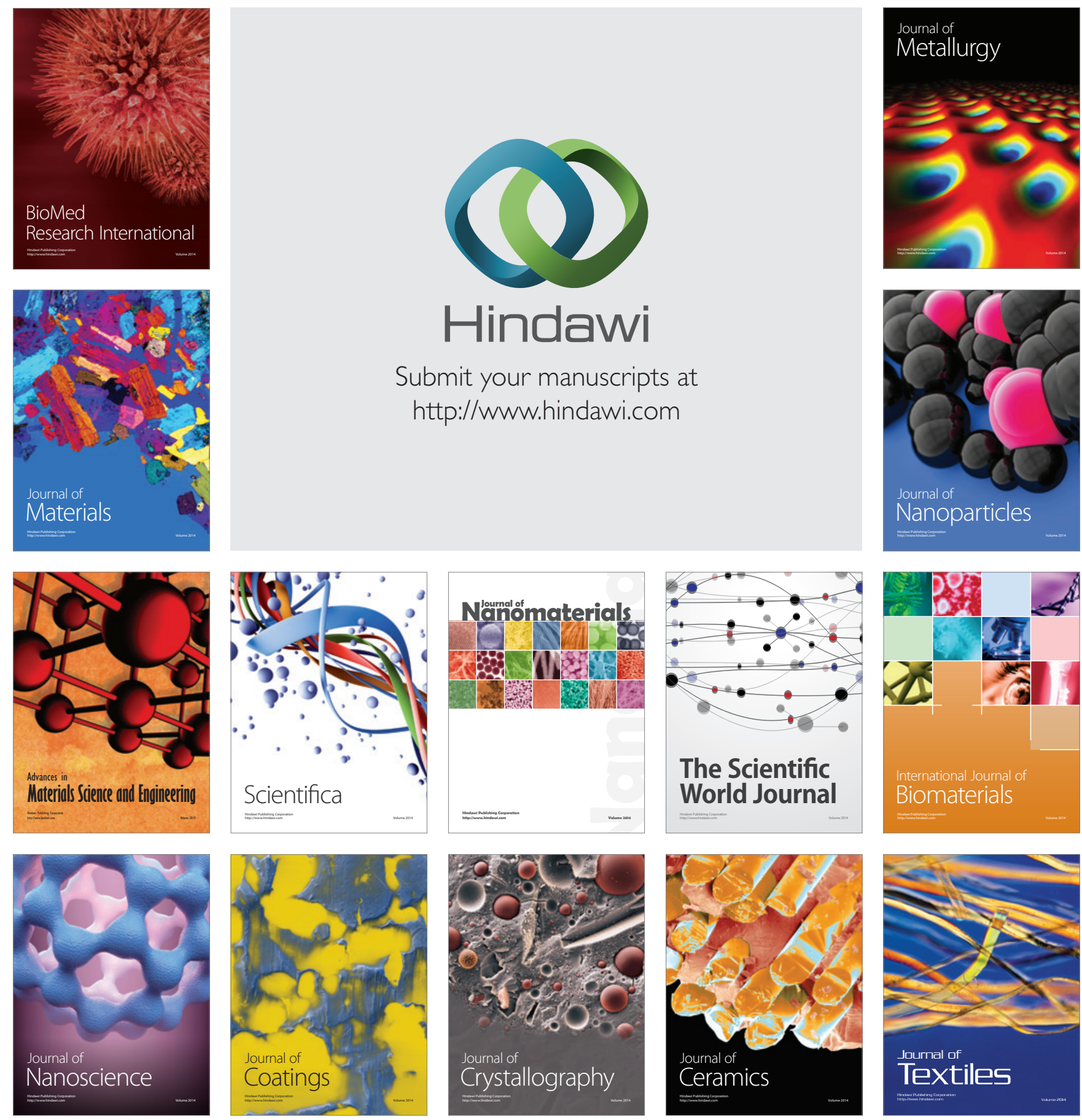